\title{
ARTICLE
}

\section{Activation of tyrosine phosphatase PTP1B in pyramidal neurons impairs endocannabinoid signaling by tyrosine receptor kinase trkB and causes schizophrenia-like behaviors} in mice

\author{
Zhaohong Qin ${ }^{1}$, Li Zhang ${ }^{1}$, Shelly A. Cruz ${ }^{1}$, Alexandre F. R. Stewart (iD $^{2}$ and Hsiao-Huei Chen (iD ${ }^{1}$
}

\begin{abstract}
Schizophrenia is a debilitating disorder affecting young adults displaying symptoms of cognitive impairment, anxiety, and early social isolation prior to episodes of auditory hallucinations. Cannabis use has been tied to schizophrenia-like symptoms, indicating that dysregulated endogenous cannabinoid signaling may be causally linked to schizophrenia. Previously, we reported that glutamatergic neuron-selective ablation of Lmo4, an endogenous inhibitor of the tyrosine phosphatase PTP1B, impairs endocannabinoid (eCB) production from the metabotropic glutamate receptor mGluR5. These Lmo4-deficient mice display anxietylike behaviors that are alleviated by local shRNA knockdown or pharmacological inhibition of PTP1B that restores mGluR5dependent eCB production in the amygdala. Here, we report that these Lmo4-deficient mice also display schizophrenia-like behaviors: impaired working memory assessed in the $Y$ maze and defective sensory gating by prepulse inhibition of the acoustic startle response. Modulation of inhibitory inputs onto layer $2 / 3$ pyramidal neurons of the prefrontal cortex relies on eCB signaling from the brain-derived neurotrophic factor receptor trkB, rather than mGluR5, and this mechanism was defective in $L m o 4-$ deficient mice. Genetic ablation of PTP1B in the glutamatergic neurons lacking Lmo4 restored tyrosine phosphorylation of trkB, trkBmediated eCB signaling, and ameliorated schizophrenia-like behaviors. Pharmacological inhibition of PTP1B with trodusquemine also restored trkB phosphorylation and improved schizophrenia-like behaviors by restoring eCB signaling, since the CB1 receptor antagonist 1-(2,4-dichlorophenyl)-5-(4-iodophenyl)-4-methyl- $\mathrm{N}$-1-piperidinyl-1H-pyrazole-3-carboxamide blocked this effect. Thus, activation of PTP1B in pyramidal neurons contributes to schizophrenia-like behaviors in Lmo4-deficient mice and genetic or pharmacological intervention targeting PTP1B ameliorates schizophrenia-related deficits.
\end{abstract}

Neuropsychopharmacology (2020) 45:1884-1895; https://doi.org/10.1038/s41386-020-0755-3

\section{INTRODUCTION}

Schizophrenia is a complex developmental disorder caused by a number of environmental factors, including prenatal infection $[1,2]$, and genetic variants conferring susceptibility [3-6]. Although psychosis (e.g., hallucinations, delusions, and disorganized behavior) is the most striking clinical feature of schizophrenia in young adults, impaired cognition, manifest as early as age 3-17 years, is now recognized as the core domain of dysfunction in the illness [7-9].

Anxiety is also highly prevalent in schizophrenia ( 38\%) [10]. Cannabis is commonly used by post-traumatic stress disorder patients to relieve anxiety as a form of self-medication [11]. Similarly, cannabis use is high among schizophrenics 26-49\% [12-14] and may provide temporary relief of their anxiety, but chronic use worsens schizophrenia in the long term [15]. A therapeutic strategy that improves anxiety and other symptoms of schizophrenia would be ideal.

Endogenous cannabinoids (endocannabinoids, eCB) including 2-arachidonoylglycerol (2AG) and anandamide are key retrograde lipid signals that bind to presynaptic CB1 receptor to limit both excitatory and inhibitory synaptic transmission [16-20]. Cannabis use in young adults increases the risk of schizophrenia by sixfold [21] and may trigger schizophrenia by disrupting the eCB system, in particular 2AG [22]. In line with this notion, young schizophrenia patients have increased mRNA levels of an enzyme that degrades 2AG [22].

Patients with schizophrenia have aberrant sensorimotor gating and impaired prepulse inhibition (PPI) of the acoustic startle response [23]. Impaired PPI is also evident in animal models useful for the study of schizophrenia [24-27]. Deficient eCB signaling may contribute to many schizophrenia-like features in mice. Ablation of the CB1 receptor produces schizophrenia-like deficits, including cognitive inflexibility [28], reduced PPI [29], and anxiety [30]. Social isolation stress suppresses PPI in rats and disrupts eCB signaling [24] with reduced 2AG levels in the prefrontal cortex (PFC) [31]. Conversely, impaired PPI can be restored by a CB1 receptor agonist in psychosocially stressed mice [25].

Mice with ablation of the endogenous PTP1B inhibitor LMO4 (LKO) in glutamatergic neurons develop severe early onset anxiety-like behaviors due to impaired 2AG production from the

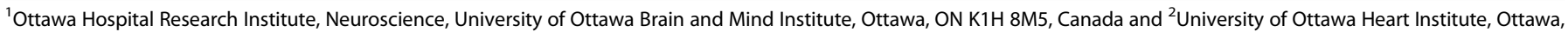
ON K1Y 4W7, Canada

Correspondence: Alexandre F. R. Stewart (astewart@ottawaheart.ca) or Hsiao-Huei Chen (hchen@uottawa.ca)

Received: 28 April 2020 Revised: 19 June 2020 Accepted: 24 June 2020

Published online: 1 July 2020 
metabotropic glutamate receptor mGluR5 in the basolateral amygdala (BLA) [18]. Knockdown of PTP1B mRNA or a selective PTP1B inhibitor at the BLA restored eCB production and alleviated anxiety in LKO mice. Similarly, wild-type mice subjected to chronic stress also displayed anxiety-like behaviors that could be ameliorated by a PTP1B inhibitor [18].

Here we tested whether disrupted eCB signaling in LKO mice produces schizophrenia-like deficits in memory and sensorimotor gating beyond anxiety. We focused on layer $2 / 3$ neurons of the PFC that integrate thalamocortical and cortico-cortical inputs $[32,33]$ important for working memory and sensorimotor gating $[34,35]$. Furthermore, $L 2 / 3$ pyramidal neurons modulate synaptic inputs by producing $e C B$ from the tyrosine receptor kinase trkB, rather than mGluR5 [36]. Since $L m o 4$ ablation activates PTP1B and PTP1B inhibits trkB signaling [37], we asked whether trkBdependent $\mathrm{eCB}$ signaling is disrupted in LKO mice and whether targeting PTP1B might restore trkB signaling and ameliorate schizophrenia-related negative phenotypes.

\section{MATERIALS AND METHODS}

Transgenic mice

Camk2aCre ${ }^{+/-}$mice [38] were bred with $\mathrm{LMO}^{\text {flox/flox }}$ mice (gift from Jane Visvader [39]), PTP1B ${ }^{\text {flox/flox }}$ mice (gift from Benjamin Neel [40], Jackson Labs \#012679), and LMO4 $4^{\text {flox/flox }} /$ PTP1B 1 flox/flox mice, to obtain LKO [18], PKO [41], double knockout (DKO) mice, respectively. All procedures in mice were approved by the University of Ottawa Animal Care Committee in accordance with guidelines of the Canadian Council on Animal Care.

\section{Behavior tests}

Mice aged 6-12 weeks of both sexes were subjected to the Ymaze test followed the next day by PPI of the acoustic startle response. Investigators were blinded to genotype. For the Y-maze test, mice were placed in an apparatus consisting of three identical arms $\left(38 \times 7.6 \mathrm{~cm}^{2}\right)$ arranged at $120^{\circ}$ (Fig. 1a, inset) with 70 lux illumination. Mice were videotaped for $8 \mathrm{~min}$ and movements were analyzed using Ethovision software (Noldus). The percent spontaneous alternations over the maximum number of arm switches during exploration were taken as a measure of active retrograde working memory.

For PPI, mice were placed in a cylindrical holder with an attached electrostatic sensor to quantify the startle response by body flinch (SR-Lab Startle Response System). A 5 min startle habituation time at the beginning of each test was to acclimate the mice to a consistent acoustic environment of $65 \mathrm{~dB}$ background noise. Three weak auditory stimuli (prepulse, 69, 73, or 81 $\mathrm{dB}$ tones of 20 ms duration) were randomly administered $100 \mathrm{~ms}$ before the startle stimulus tone $(120 \mathrm{~dB}$ for $40 \mathrm{~ms})$ (Fig. 1d). The amplitude of the mouse's movement was recorded and PPI was calculated as the percentage of the response to a loud tone that was lost after a prepulse tone.

Social interaction was assessed as we described recently [33]. Mice were habituated for $5 \mathrm{~min}$ in the arena with empty mesh cages. The time they spent at the interactive zone $(8 \mathrm{~cm}$ away from each side of the mesh cage) was recorded over $5 \mathrm{~min}$. The discriminative index for sociability was calculated by the formula $(A-B) /(A+B)$, where $A$ is the time spent in the interaction zone with a littermate and $B$ without any social target in the mesh cage. The discriminative index for novelty was calculated by the formula $(A-B) /(A+B)$, where $A$ time spent in the interaction zone with novel strangers and $B$ with familiar littermates.

\section{Drugs}

Systemic delivery to 6-12-week old mice was achieved by intraperitoneal injection of trodusquemine $(5 \mathrm{mg} / \mathrm{kg}$, gift from Zasloff [41-43]) with or without the CB1 antagonist 1-(2,4dichlorophenyl)-5-(4-iodophenyl)-4-methyl- $\mathrm{N}$-1-piperidinyl-1H- pyrazole-3-carboxamide (AM251) (3 mg/kg in 20\% DMSO, 5\% Tween-80 in saline). All drugs were freshly prepared and administered $80 \mathrm{~min}$ (AM251) or $1 \mathrm{~h}$ (trodusquemine) before behavior tests. For intracortical delivery to the PFC, mice were anesthetized with isoflurane and cannulas were implanted stereotactically (coordinates: anteroposterior $1.8 \mathrm{~mm}$ from bregma; mediolateral $\pm 0.4 \mathrm{~mm}$ from the midline; dorsoventral $-2.3 \mathrm{~mm}$ from skull surface [44]) 1 week before behavior tests. Saline or trodusquemine $(20 \mu \mathrm{M} / 0.5 \mu \mathrm{L} / \mathrm{side})$ was infused bilaterally using dual syringe pump (GenieTouch) driving 2 Hamilton 1 $\mu \mathrm{L}$ syringes with 22-Gauge needles into the PFC at a rate of 0.25 $\mu \mathrm{L} / \mathrm{min}$. To ensure minimal leak into surrounding brain areas, injection needles remained in the brain for $1 \mathrm{~min}$ after injection before being slowly withdrawn.

\section{Electrophysiology}

Coronal brain sections $(300 \mu \mathrm{M})$ containing PFC were prepared from 4- to 10-week-old mice as described [18, 45, 46]. ACSF contained (in $\mathrm{mM}): 119 \mathrm{NaCl}, 26.2 \mathrm{NaHCO}, 11$ glucose, $2.5 \mathrm{KCl}, 2.5 \mathrm{CaCl} 2,1.3$ MgSO4, $1 \mathrm{NaH} 2 \mathrm{PO} 4$, and was equilibrated with 95\% $\mathrm{O} 2$ and 5\% CO2 at room temperature. Unless indicated otherwise, recording electrodes were filled with a solution of (in $\mathrm{mM}$ ): $100 \mathrm{CsCH} 3 \mathrm{SO} 3$, $60 \mathrm{CsCl}, 10 \mathrm{HEPES}, 0.2 \mathrm{EGTA}, 1 \mathrm{MgCl} 2,5$ QX-314 chloride, $1 \mathrm{MgATP}$, and $0.3 \mathrm{NaGTP}$ (pH 7.3 adjusted with $\mathrm{CsOH}, 275 \mathrm{mOsM}$ ).

Whole-cell recordings from layer 2/3 PFC pyramidal neurons were acquired with a Multiclamp 700B amplifier and Digidata 1440 interface (Molecular Devices) and analyzed using pClampfit 10.7. Recordings were filtered at $3 \mathrm{kHz}$, digitized at $10 \mathrm{kHz}$. Access resistance was continuously monitored by applying a $75 \mathrm{~ms}, 5 \mathrm{mV}$ hyperpolarizing pulse $250 \mathrm{~ms}$ before evoking the eIPSCs. Cells were used only if the access resistance was below $20 \mathrm{M} \Omega$.

For current clamp experiments, patch pipette solution contained (in mM): 115 K-gluconate, $20 \mathrm{KCl}, 2 \mathrm{MgCl} 2,10 \mathrm{HEPES}, 10 \mathrm{Na}$ phosphocreatine, $4 \mathrm{NaATP}$, and $0.3 \mathrm{NaGTP}, \mathrm{pH}$ adjusted to 7.3 with $\mathrm{KOH}$. The GABAA receptor antagonist bicuculline was included in bath solution to isolate glutamatergic currents. To evaluate the neuron excitability, a series of brief currents with increasing amplitude (50-400 pA, $500 \mathrm{~ms}$ ) were injected into PFC layer $2 / 3$ pyramidal neurons to induce the number of reliable action potential firings during the depolarizing steps. Data were plotted to fit a sigmoid function with equation $f=a /(1+\exp (-(x-x 0) / b))$ to calculate the slope $(b)$ and obtain the threshold $(x 0)$ of the electrical current required to reach $50 \%$ of the maximum firing frequency $(a)$.

For voltage clamp to measure spontaneous or miniature excitatory postsynaptic currents (sEPSC or mEPSC, respectively), internal solution contained (in $\mathrm{mM}$ ): $115 \mathrm{CsMeSO} 4,2.8 \mathrm{NaCl}, 0.4$ EGTA, 5 TEA-Cl, 20 HEPES, 3.0 MgATP, 0.5Na2GTP, $10 \mathrm{Na}$ phosphocreatine, $\mathrm{pH}$ adjusted to 7.3 with $\mathrm{CsOH}$. mEPSC were acquired at $-70 \mathrm{mV}$ in control ACSF solution supplemented with tetrodotoxin (TTX). Only $>7.5 \mathrm{pA}$ events, which excluded the events beyond the detection limit of the noisiest recordings, were included in the analysis.

For voltage clamp to measure evoked inhibitory events, internal solution contained (in mM): $100 \mathrm{CsCH} 3 \mathrm{SO}, 60 \mathrm{CsCl}, 10 \mathrm{HEPES}, 0.2$ EGTA, $1 \mathrm{MgCl} 2,5$ QX-314 chloride, $1 \mathrm{MgATP}$, and $0.3 \mathrm{NaGTP}(\mathrm{pH}$ 7.3 adjusted with $\mathrm{CsOH}, 275 \mathrm{mOsM}$ ). For paired-pulse ratio (PPR), depolarization-induced suppression of inhibition (DSI), and longterm depression of the inhibitory (LTDi) recordings, cells were held at $-70 \mathrm{mV}$. Cl-reversal potential was set around $-16 \mathrm{mV}$ to enable sufficient driving force to evoke IPSC events. PPR (second and first inhibitory postsynaptic current (IPSC2/IPSC1)) was calculated by averaging the ratio of paired IPSCs amplitudes from eight traces at different interstimulus intervals $(50,100,250$, and $500 \mathrm{~ms})$. The AMPA receptor antagonist 2,3-dihydroxy-6-nitro-7-sulfamoylbenzo [f]quinoxaline-2,3-dione (NBQX) and NMDA receptor antagonist (2R)-amino5-phosphonopentanoate (APV) were included in the bath solution to isolate inhibitory postsynaptic events. 
<smiles>ClCC12C=CC(C1)C2</smiles>

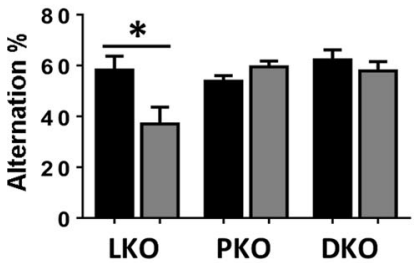

d

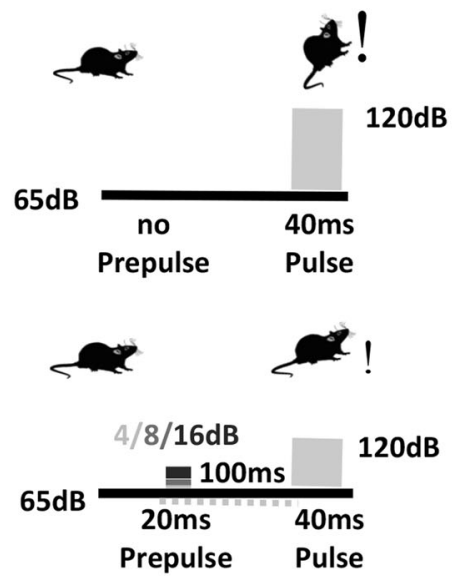

b

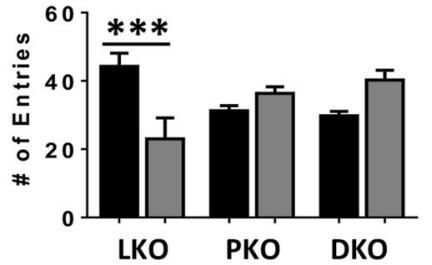

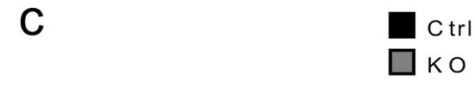

$\mathrm{tr}$

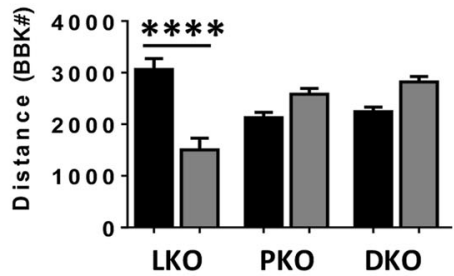

e

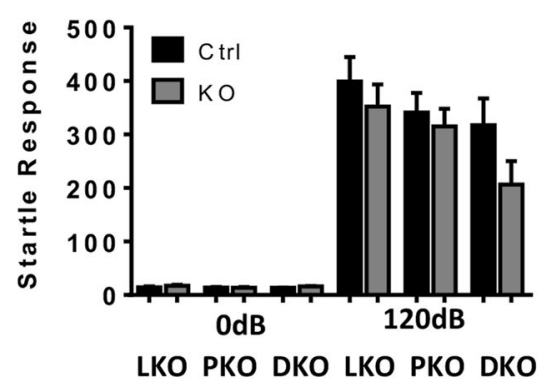

f

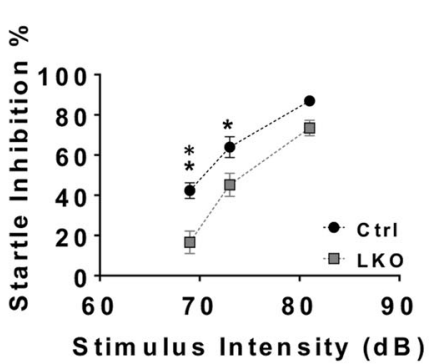

g

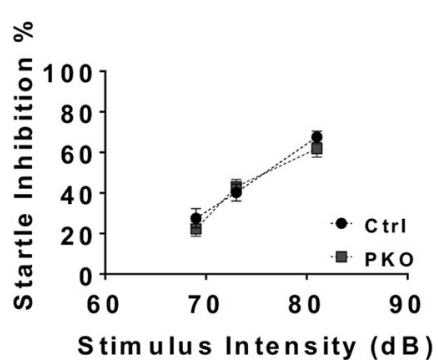

h

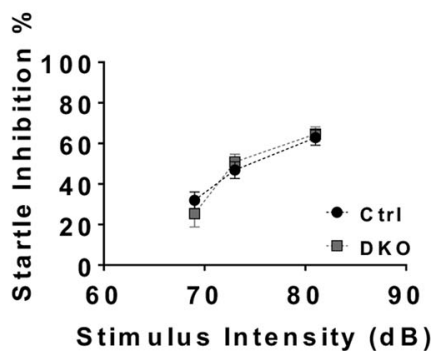

Fig. 1 Schizophrenia-like phenotypes induced by Lmo4 ablation are rescued by PTP1B deletion. a Spatial working memory, assessed by spontaneous alternation in a Y maze (inset), was impaired in LMO4 knockout mice (LKO) and this deficit was rescued in LMO4 and PTP1B double knockout mice (DKO). Ablation of PTP1B alone (PKO) did not affect spatial memory. Two-way analysis of variance (ANOVA), genotype effect $F_{2,43}=4.719, p=0.0140, \mathrm{Ctrl} / \mathrm{KO}$ effect $F_{1,43}=4.356, p=0.0428$, interaction $F_{2,43}=5.835, p=0.0057$. Tukey's test ${ }^{*} p=0.0172$. b Entries to the $Y$ maze and $c$ distances traveled as measured by numbers of beam break (BBK\#) were reduced in LKO mice compared to wild-type controls (Ctrl) and were rescued in DKO mice. Two-way ANOVA for (b): interaction $F_{2,45}=14.36, p<0.0001$ and for (c) $F_{2,45}=31.56, p<0.0001$. Tukey's test ${ }^{* *} p=0.0005$ (b) and ${ }^{* * * *} p<0.0001$ (c). d Diagram of prepulse inhibition of the acoustic startle response. e Startle responses were similar between groups. Sensorimotor gating function, evaluated by prepulse inhibition of the acoustic startle response, is deficient in LKO mice (f), unaffected in PKO mice $(\mathbf{g})$, and rescued in DKO mice (h). Two-way ANOVA for (f): stimulus intensity effect $F_{2,78}=55.03, p<0.0001$, genotype effect $F_{1,78}=23.93, p<0.0001$, Tukey's test ${ }^{* *} p=0.0039(69 \mathrm{~dB})$, ${ }^{*} p=0.0431$ (73 dB). Data are mean \pm SEM from $n=7-13$ mice per group.

DSI was induced by a 4-s depolarizing step $(-70-0 \mathrm{mV})$. The response was measured with a single stimulation delivered every $3 \mathrm{~s}$. DSI was calculated by the average magnitude of three responses measured immediately after the depolarization step. Some DSIs were obtained from the paired recordings before and after bath application of (RS)-3, 5-dihydroxyphenylglycine (DHPG, $50 \mu \mathrm{M})$ and 7,8-dihydroxyflavone (DHF, $30 \mu \mathrm{M})$.

For DHF-LTDi, before and after DHF $(30 \mu \mathrm{M})$ bath application, successive IPSCs were induced by testing stimuli of $0.067 \mathrm{~Hz}$ at $10 \mu$ s duration from a stimulation bipolar electrode inserted into layer V. All recorded IPSCs were normalized to their own averaged baseline level and plotted as a function of time. The last $3 \mathrm{~min}$ of the recording were compared to the 3-min baseline to evaluate DHF-induced alteration in GABA synaptic events.
The following chemicals and their concentrations were used for recording: APV $(50 \mu \mathrm{M})$, NBQX $(5 \mu \mathrm{M})$, DHPG $(50 \mu \mathrm{M}), 7,8-$ Dihydroxy-2-phenyl-4H-1-benzopyran-4-one (DHF, $30 \mu \mathrm{M}$, MilliporeSigma), AM251 (3 $\mu \mathrm{M})$, [R-( $\left.\left.R^{*}, S^{*}\right)\right]-5$-(6,8-Dihydro-8-oxofuro[3,4-e]1,3-benzodioxol-6-yl)-5,6,7,8-tetrahydro-6,6-dimethyl-1,3-dioxolo [4,5-g]isoquinolinium bromide (bicuculline, $20 \mu \mathrm{M}$ ), and Octahydro-12-(hydroxymethyl)-2-imino-5,9:7,10a-dimethano-10aH-[1, 3] dioxocino [6,5-d] pyrimidine-4,7,10,11,12-pentol (TTX, $1 \mu \mathrm{M})$.

Western blot analysis

PFC protein extracts from 2-month-old mice were prepared for western blot analysis as described $[47,48]$. Primary monoclonal antibodies to pY706-trkB (Abcam, ab197072), trkB (Abcam, ab187041), PTP1B (Abcam, ab245984) and to actin (Sigma, ab179467) were used. 
a

WT

LKO

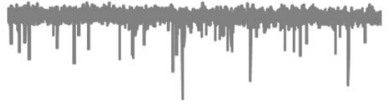

PKO

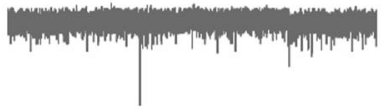

DKO
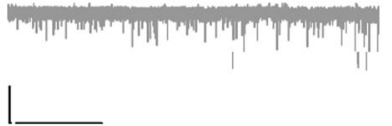

f

WT

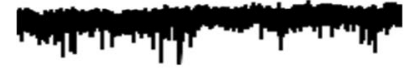

LKO

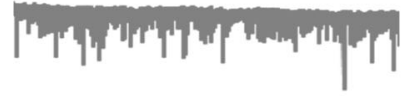

PKO

DKO
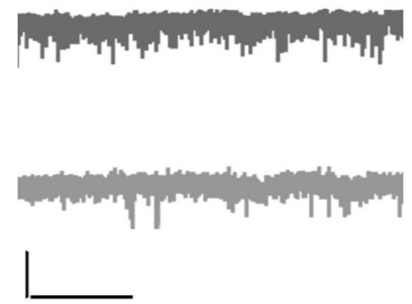

$\mathrm{k}$

WT

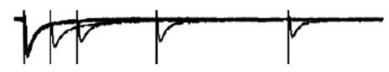

LKO

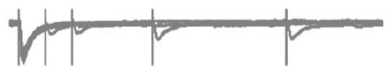

PKO

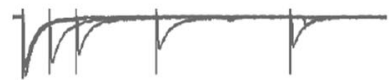

DKO

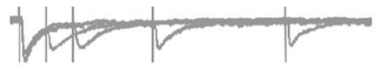

b

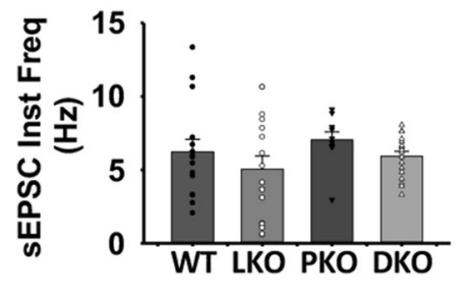

d

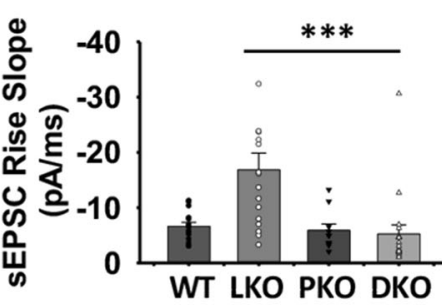

9
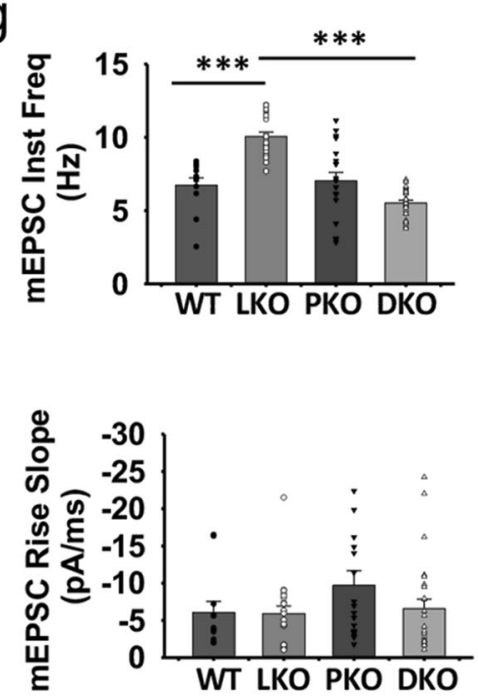

C

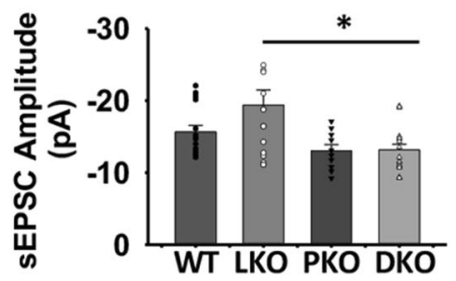

e

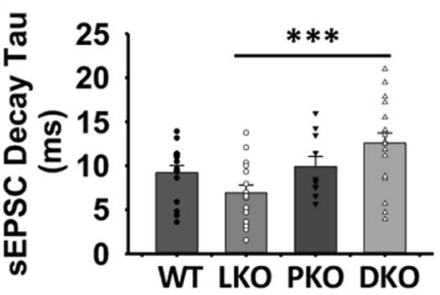

$\mathrm{h}$

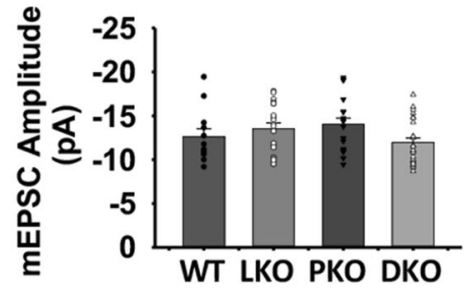

j

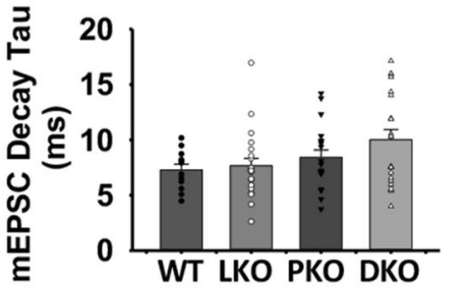

Statistical analysis

Statistical analysis was performed with Prism 6.01 or SigmaPlot 14.0 software. In all cases, $n$ refers to an experiment on a single cell or a single mouse. All results are expressed as mean \pm standard error of the mean (SEM). Statistical significance was assessed by two-tailed Student's $t$ tests (unpaired or paired, where

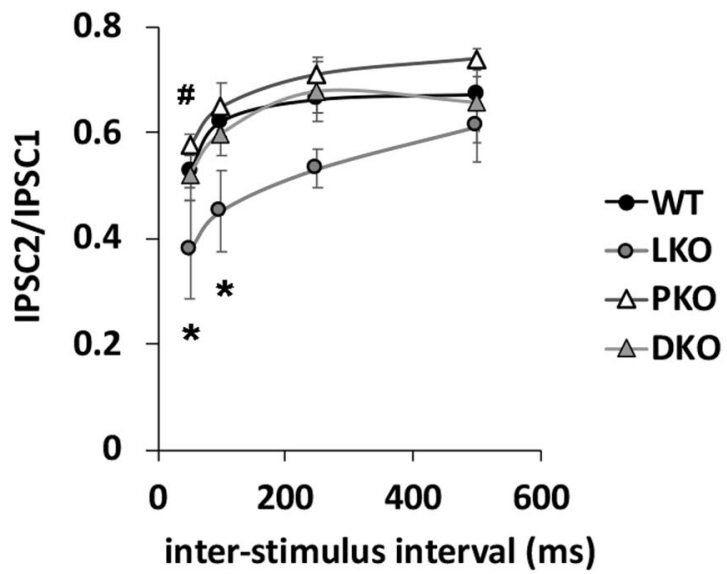

appropriate), one-way analysis of variance (ANOVA), Kruskal-Wallis one-way ANOVA on ranks or two-way ANOVA. Bonferroni's, Tukey's, Dunn's, or Holm-Sidak post hoc tests were used for multiple comparisons when appropriate. Only significant main effects, interactions, or post hoc comparisons were presented. 
Fig. 2 Increased presynaptic release in mice with Lmo4 ablation was normalized with PTP1B ablation. a Sample traces of spontaneous excitatory postsynaptic current (sEPSC) recorded from WT, LKO, PKO, and DKO mice. Scale bars: 20 pA/15 s. Spontaneous excitatory inputs to prefrontal cortex layer 2/3 pyramidal neurons in LKO mice were compared to WT: $\mathbf{b}$ instant frequency was not affected, $\mathbf{c}$ amplitude and $\mathbf{d}$ rise slope were increased, and e decay tau was decreased. Kruskal-Wallis one-way ANOVA on ranks for (c): $H=10.844, p=0.013$. Dunn's pairwise comparison ${ }^{*} p=0.026$. Kruskal-Wallis one-way ANOVA on ranks for $(\mathbf{d}): H=22.370, p<0.001$. Dunn's pairwise comparison ${ }^{* * *} p<0.001$. Oneway ANOVA for $(\mathbf{e}): F_{3,55}=6.003, p=0.001$. Bonferroni's $t$ test ${ }^{* * *} p<0.001$. f Sample traces of miniature excitatory postsynaptic currents (mEPSC). Scale bar: 20 pA/10 s. g Frequency of mEPSC was increased in LKO mice and normalized in DKO mice. Kruskal-Wallis one-way ANOVA on ranks: $H=42.517, p<0.001$, Dunn's pairwise comparison ${ }^{* * *} p<0.001$. No difference in amplitudes (h), rise slope (i), or decay tau (j) was observed. k Current traces (average of eight responses) of GABAR-mediated eIPSCs induced by paired pulses delivered at different interstimulus intervals (50, 100, 250, and $500 \mathrm{~ms}$ ), obtained from WT, LKO, PKO, and DKO mice. Scale bar: 50 pA/100 ms. I Average paired-pulse ratios (IPSC2/IPSC1) were obtained at different interstimulus intervals. Compared to WT, PPR was reduced in LKO mice, increased in PKO mice, and normalized in DKO mice. Two-way ANOVA for stimulus interval effect $F_{3,63}=4.970, p=0.0037$, genotype effect $F_{1,63}=22.77, p<0.0001$; Tukey's test: ${ }^{*} p=0.0283$ (50 ms, LKO), 0.0241 (100 ms, LKO). ${ }^{\#} p=0.0022$ (50 ms, PKO). Data are means \pm SEM of $n=10-18$ cells (a-e), $12-25$ cells $(\mathbf{f}-\mathbf{j}), 38 \mathrm{Ctrl}, 8 \mathrm{LKO}, 8$ PKO, 13 DKO (I) from $n=4-12$ mice per genotype.

\section{RESULTS}

Neuronal PTP1B activation causes cognitive and sensory gating deficits in LKO mice

To control for possible differences in backgrounds, in all behavior studies, each genotype was compared to its own littermate "wildtype" (i.e., non-floxed allele) control. Mice with projection neuronspecific ablation of the endogenous PTP1B inhibitor LMO4 (LKO) have impaired working memory as assessed by the Y-maze test (Fig. 1a-c) and this deficit was rescued by deletion of PTP1B in the same projection neurons lacking Lmo4 (DKO). Interestingly, deleting PTP1B in projection neurons (PKO) did not affect $Y$ maze performance compared to littermate controls. Next, we examined sensorimotor gating in the acoustic startle response (Fig. 1d). While all mice showed a similar startle response to a loud noise (Fig. 1e), PPI of the startle response was markedly impaired in LKO mice compared to littermate WT controls (Fig. 1f). The PKO mice that ablate PTP1B in projection neurons showed no deficit in PPI compared to littermate WT controls (Fig. 1g). The DKO mice that ablate both LMO4 and PTP1B in the same projection neurons also showed no deficit in PPI (Fig. 1h). We did not observe a sex difference in behavioral deficits. Of note, locomotor activity is not different in LKO mice compared to WT littermate controls, as we reported previously [18]. In addition, no difference in social interaction or social novelty was observed in LKO mice (Supplementary Fig. S1). While LKO mice did not display social anxiety-like behaviors, these mice do display a generalized form of anxiety-like behaviors, as measured by the elevated plus maze, open field, and light/dark preference tests, as we reported previously [18]. Thus, in addition to generalized anxiety-like behaviors, LKO mice display two other negative schizophrenialike phenotypes: impaired working memory and sensorimotor gating.

Increased excitability of L2/3 PFC pyramidal neurons of LKO mice To assess the consequence of $L m o 4$ ablation in glutamatergic projection neurons, intrinsic properties of L2/3 PFC pyramidal neurons were measured (Supplementary Fig. S2). We observed increased membrane resistance, reduced resting membrane potential, changes in the current-voltage curves, and increased excitability with reduced threshold of activation in LKO mice. These altered properties were largely restored by PTP1B ablation in DKO mice.

Increased synaptic release to L2/3 PFC pyramidal neurons of LKO mice

We next determined the consequence of Lmo4 ablation of synaptic inputs to L2/3 PFC pyramidal neurons by recording spontaneous (sEPSC, Fig. 2a-e) and miniature (mEPSC, Fig. $2 \mathrm{f}-\mathrm{j}$ ) excitatory postsynaptic currents. For all electrophysiological studies, we did not find differences between the different littermate controls and data were pooled from all littermate controls and referred to as "WT." While there was no change in the frequency of sEPSC (Fig. 2b), their amplitude was increased (Fig. 2c) in LKO mice. An increased rise slope (Fig. 2d) and decreased decay tau (Fig. 2e) were also observed in LKO mice. These changes in SEPSC were rescued in DKO mice.

sEPSC were recorded in the presence of bicuculline (a GABA receptor antagonist) to remove inhibitory inputs and to isolate excitatory inputs to the pyramidal neuron. However, excitatory neural activity can affect presynaptic release as well as the postsynaptic response. To silence neural network activity, mEPSC (Fig. $2 \mathrm{f}-\mathrm{j}$ ) were recorded in the presence of the voltage-gated sodium channel blocker TTX, so that a change in frequency indicates a change in presynaptic release, whereas a change in amplitude reflects a postsynaptic change [49]. In LKO mice, mEPSC frequency is increased (Fig. 2g), with no change in their amplitudes (Fig. 2h), rise slope (Fig. 2i), or decay tau (Fig. 2j). This indicates that presynaptic glutamate release is increased in the absence of an altered postsynaptic response. Importantly, this change in mEPSC observed in LKO mice was also normalized in DKO mice.

Spontaneous IPSC showed a reduced frequency in LKO mice that was rescued in DKO mice, with no change in amplitude, rise time or decay tau (Supplementary Fig. 3a-d). While we did not measure mIPSC, we believe the reduced sIPSC frequency reflects a change in inhibitory circuits as an indirect outcome of increased glutamatergic neuron excitability (see model, Supplementary Fig. 3e).

We next asked whether evoked neurotransmitter release is affected in LKO mice. Previous work by Wilson and Nicoll showed that the PPR (IPSC2/IPSC1), inversely correlated with the evoked release probability, is sensitive to the basal tone of eCB signaling through presynaptic CB1 receptors [46]. Since $L m o 4$ is ablated in glutamatergic but not in GABAergic neurons, we thought the best way to compare changes in release probability would be to measure evoked GABAergic inputs because their intrinsic properties should not be affected in LKO mice. Paired-pulse stimuli were delivered at different intervals to measure the amplitudes of the IPSC1 and IPSC2 (Fig. 2k). We found that PPR was markedly decreased in LKO mice (Fig. 2l), indicating increased GABA release probability. While the PPR in PKO mice was slightly increased relative to littermate controls, DKO mice normalized the PPR and the inhibitory release probability (Fig. 2l). It should be noted that reduced spontaneous IPSC frequency does not necessarily conflict with increased evoked GABA release probability, as measured by the PPR since spontaneous and evoked neurotransmitter release are known to differ [49]. Taken together, these studies reveal that both excitatory and inhibitory presynaptic release were increased at $L 2 / 3$ pyramidal neurons of the PFC in LKO mice and were normalized by PTP1B ablation in the same neurons of DKO mice. Since Lmo4 was not ablated in inhibitory neurons, increased synaptic release from these neurons is likely an indirect effect caused by postsynaptic excitatory neurons lacking Lmo4. 
a1

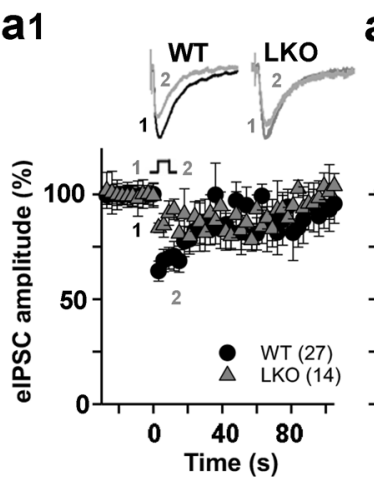

a2
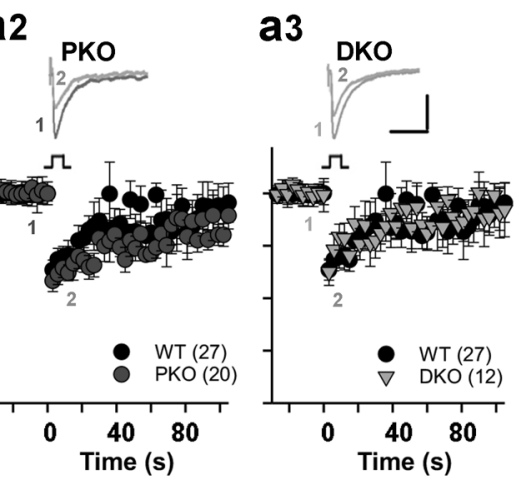

a4
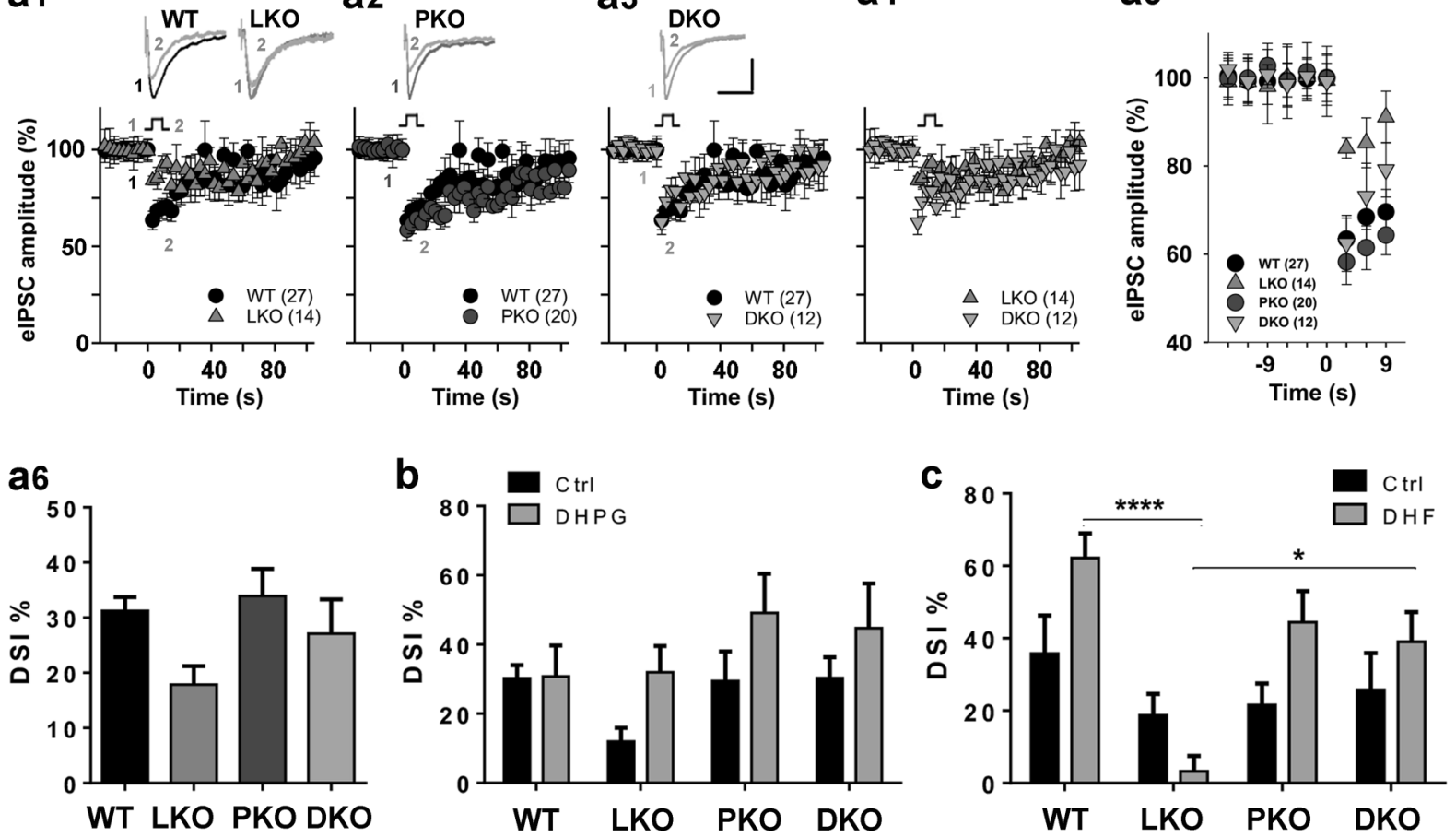
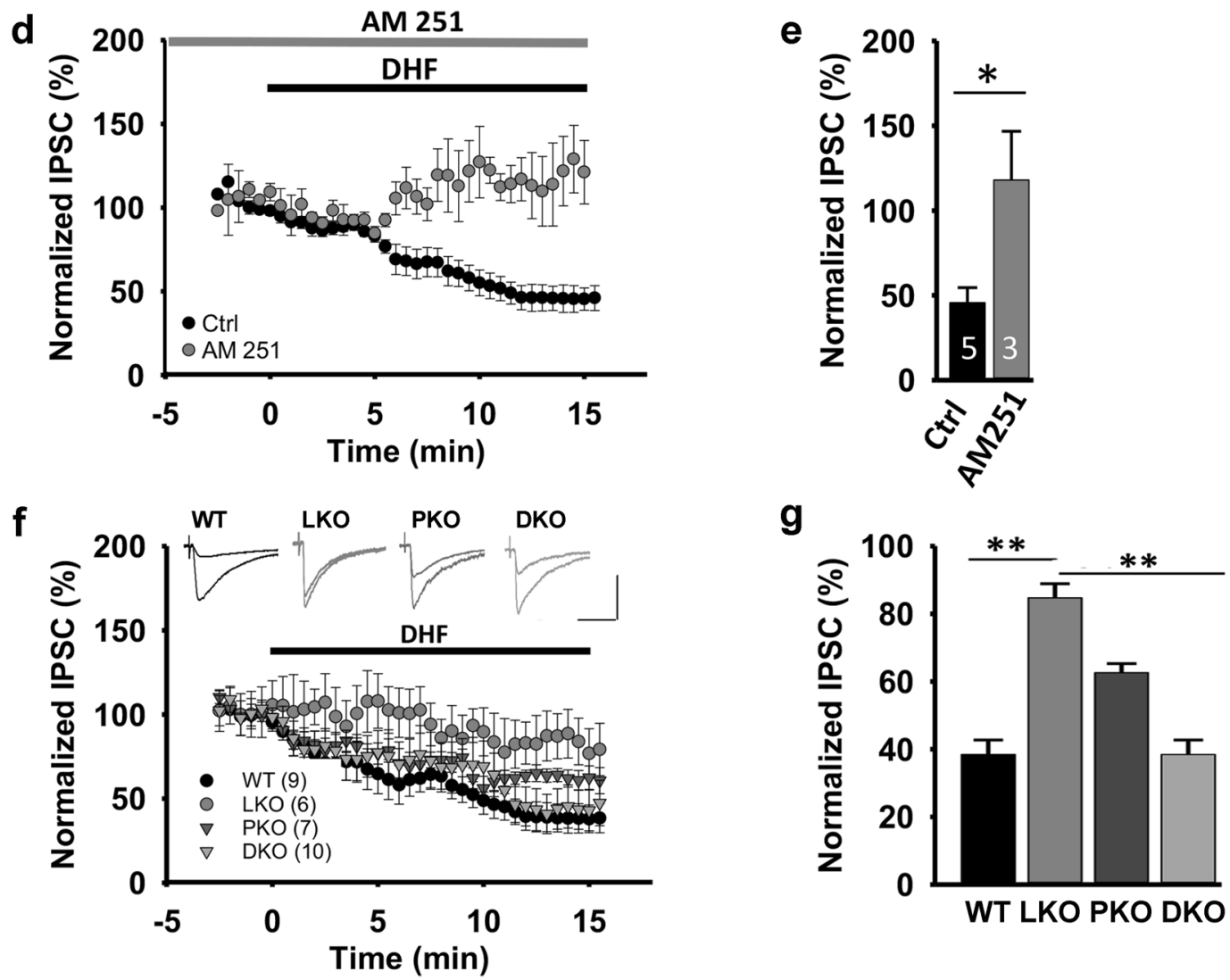

Impaired trkB-mediated $\mathrm{eCB}$ signaling and modulation of the synaptic response of L2/3 PFC neurons in LKO mice

Previously, we reported that PTP1B activation in LKO mice causes reduced $\mathrm{ECB}$ production from mGluR5 in the BLA and that PTP1B shRNA-mediated knockdown could restore eCB-mediated a5

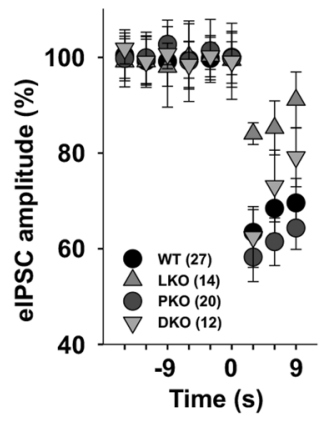

1889 
Fig. 3 TrkB-dependent synaptic modulation at L2/3 PFC pyramidal neurons by eCB mobilization is deficient in LKO mice but restored in DKO mice. a1-6 Depolarization-induced suppression of inhibition (DSI) measured under basal conditions. Sample traces of elPSC before (1) and after (2) depolarization (scale $100 \mathrm{pA} / 50 \mathrm{~ms}$ ) are shown above the time course of recorded elPSC amplitudes comparing different genotypes (a1-4). (a5) Enlarged results from (a1-4) showing first three elPSC after depolarization, averaged in (a6). One-way ANOVA: genotype effect $F_{3,86}=2.741, p=0.0482$. Post hoc Bonferroni pairwise comparison did not reach significance between WT and LKO, $p=0.0562$. b LKO did not affect the DSI in response to mGluR5 agonist DHPG $(50 \mu \mathrm{M})$. Two-way ANOVA: DHPG effect $F_{3,115}=3.306, p=0.0228$. Tukey's multiple comparisons test revealed no significant pairwise difference. c LKO blocked the DSI response to the trkB agonist DHF (30 $\mu \mathrm{M})$. Two-way ANOVA: genotype effect $F_{3,44}=9.617, p=0.0001$, DHF effect $F_{1,44}=4.862, p=0.0327$, interaction $F_{3,44}=3.744, p=0.0176$. Tukey's multiple comparisons test ${ }^{* * *} p<0.0001 ;{ }^{*} p=0.0347$. d Pretreatment with CB1 receptor antagonist AM251 prior to DHF blocks DHF-induced LTDi. Ctrl vehicle control. e Average values of normalized eIPSC in the last 3 min of DHF $(30 \mu \mathrm{M})$ exposure. Unpaired $t$-test ${ }^{*} p=0.025$. f DHF-induced long-term depression of IPSC (LTDi) was markedly attenuated in LKO mice compared to littermate WT, PKO, and DKO PFC neurons. Top: current traces depicting GABA-mediated elPSCs before and 15 min after DHF (30 $\mu \mathrm{M})$ application from WT, LKO, PKO, and DKO (100 pA/25 ms). g Normalized eIPSC values were averaged for the last 3 min of DHF treatment. Kruskal-Wallis one-way ANOVA on ranks, $H=46.851, p<0.001$. Dunn's pairwise comparison ${ }^{* *} p<0.001$. Data are means \pm SEM of $n=9-21$ cells (a) or as indicated (e, f) from 4-6 (a-c, f) or 2-3 (d) mice per group.

signaling. In contrast to what we observed in the BLA, the mGluR5 agonist DHPG did not further enhance DSI in L2/3 pyramidal neurons of the PFC in wild-type mice (Fig. 3b). On the other hand, DSI was enhanced by the trkB receptor agonist DHF [50] in wildtype mice and this response was absent in LKO mice (Fig. 3c).

Activation of trkB signaling by DHF increases eCB signaling to presynaptic $C B 1$ receptors to attenuate GABA release [51]. This causes LTDi current, an effect that is blocked by the CB1 receptor antagonist AM251 (Fig. 3d, e). The effect of DHF on LTDi was markedly reduced in PFC neurons of LKO mice (Fig. $3 \mathrm{f}, \mathrm{g}$ ), suggesting that trkB-mediated $e C B$ signaling from $L 2 / 3$ PFC neurons is impaired with ablation of LMO4. Together, these findings lead us to conclude that impaired eCB signaling in PFC $L 2 / 3$ pyramidal neurons of LKO mice could be due to a deficit in trkB signaling caused by PTP1B activation, since it could be restored by simultaneous ablation of PTP1B.

PTP1B ablation or pharmacological inhibition restores tyrosine phosphorylation of trkB in LKO mice

Phosphorylation of trkB at tyrosine 706 is tied to its activation by the endogenous ligand brain-derived neurotrophic factor and PTP1B dephosphorylates this residue and inactivates trkB signaling [37]. Thus, we next compared the basal levels of trkB tyrosine phosphorylation by immunoblot analysis as a readout of its activity. PFC protein extracts of LKO mice show reduced levels of p-trkB (Fig. 4a). Ablation of PTP1B restored p-trkB levels in DKO mice. Similarly, LKO mice treated with the PTP1B inhibitor trodusquemine showed restored $\mathrm{p}$-trkB levels relative to vehicletreated controls (Fig. 4b).

Pharmacological inhibition of PTP1B rescues schizophrenia-like behaviors in LKO mice

To determine whether cognitive and sensorimotor gating deficits could be ameliorated by pharmacological inhibition of PTP1B, LKO mice were treated with trodusquemine, a selective PTP1B inhibitor that crosses the blood brain barrier [18]. The alternation phenotype in the $\mathrm{Y}$ maze was restored by trodusquemine administration either by intraperitoneal (Fig. 5a) or by stereotactic injection to the PFC (Supplementary Fig. 4a), consistent with what we observed in DKO mice (Fig. 1a), indicating that PTP1B contributes to this cognitive deficit. However, in contrast to what we observed with PTP1B ablation in DKO mice (Fig. 1b, c), trodusquemine did not improve the number of entries (Fig. 5b) or the distance traveled in the $Y$ maze (Fig. $5 \mathrm{c}$ ), suggesting that these two phenotypes may be due to compensatory changes in neural circuits in LKO mice that cannot be reversed by acute pharmacological inhibition of PTP1B.

PPI of the acoustic startle response (Fig. $5 d-f$ ) was also restored by trodusquemine administration either by intraperitoneal (Fig. 5) or by stereotactic injection to the PFC (Supplementary Fig. 4). Pretreatment with the $C B 1$ receptor antagonist AM251 blocked the effect of trodusquemine (Fig. $5 \mathrm{~g}-\mathrm{I}$ ), supporting the notion that trodusquemine ameliorates schizophrenia-like behavior deficits in LKO mice by restoring eCB signaling through $C B 1$ receptors. Of note, while the vehicle (20\% DMSO/5\% Tween-80) had no effect on the number of alternations (Fig. 5j), it did suppress the number of entries (Fig. 5k) and distance traveled in the $\mathrm{Y}$ maze (Fig. 5I) compared to saline-treated LKO mice. Similarly, the vehicle also reduced the startle response (compare Fig. $5 \mathrm{j}$ to $\mathrm{d}$ ), but did not affect PPI (compare Fig. 5k to f).

\section{DISCUSSION}

Our study has shown that $\mathrm{eCB}$ signaling is important to prevent schizophrenia-like deficits in memory and sensorimotor gating. LKO mice lacking the endogenous PTP1B inhibitor (LMO4) in glutamatergic projection neurons were deficient in trkBdependent $\mathrm{eCB}$ signaling from $L 2 / 3$ pyramidal neurons of the PFC. Genetic ablation of PTP1B in the same neurons that ablate Lmo4 could prevent this deficit in trkB-dependent eCB signaling and the appearance of these schizophrenia-like deficits. Moreover, pharmacological inhibition of PTP1B by trodusquemine could restore trkB signaling and ameliorate the schizophrenia-related deficits in LMO4-deficient mice, demonstrating that these deficits are reversible in adult mice. That the CB1 receptor antagonist AM251 could block the salutary effect of trodusquemine on memory and sensorimotor gating in LKO mice argues that the main effect of trodusquemine is to restore eCB signaling.

While the involvement of tyrosine kinase receptor trkB in eCB signaling from L2/3 PFC pyramidal neurons $[36,52-54]$ and the inhibitory effect of PTP1B to block trkB-dependent signaling [37] are both well documented, the present report is the first to demonstrate that deficits in trkB-dependent $\mathrm{eCB}$ signaling can be rescued by systemic or intracortical injection of the selective PTP1B inhibitor trodusquemine. Loss of trkB-dependent 2AG signaling accounts for increased mEPSC frequency [55]. This is also consistent with increased inhibitory release probability we detected by the reduced PPR [18-20] and the reduced eCBmediated LTDi synapses [56]. It is noteworthy that the mEPSC amplitude was not affected by Lmo4 ablation in pyramidal neurons, suggesting that the number of AMPA glutamate receptors is not affected.

Electrophysiological properties of $L 2 / 3$ pyramidal neurons were affected by $L m o 4$ ablation, including a depolarized resting membrane potential in LKO compared to WT mice $(-70.3$ vs. $-73.93 \mathrm{mV}$, respectively) and a decreased membrane conductance $(9.65 \pm 0.55 \mathrm{nS}$ and $7.36 \pm 0.52 \mathrm{nS}$, respectively). While increased excitability of L2/3 PFC pyramidal neurons is consistent with their reduced membrane conductance, we cannot explain why PKO mice also have reduced conductance yet no increased excitability. The changes in the current-voltage curves in LKO compared to WT were complex mirror images to those changes in DKO compared to WT, suggesting that PTP1B deletion not only corrects the deficits of $L$ mo4 deletion but may over compensate 
a

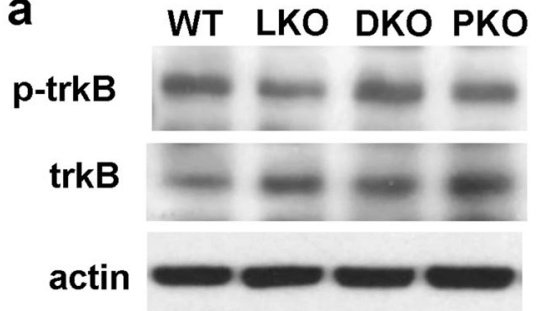

PTP1B

actin

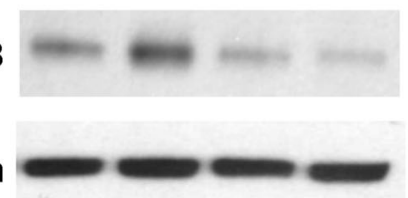

b

p-trkB

trkB

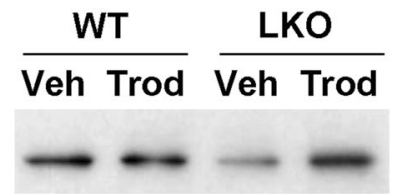

actin
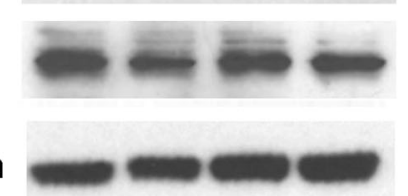
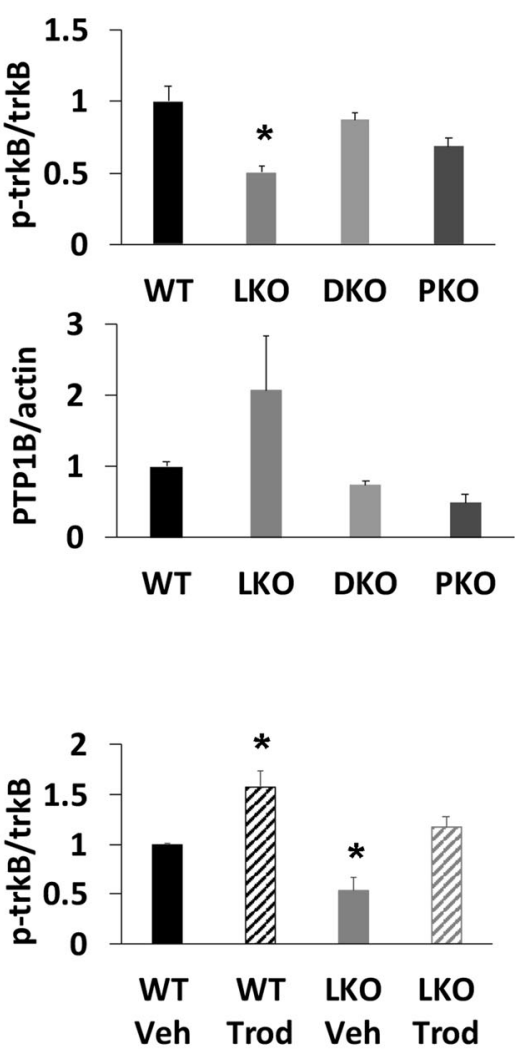

Fig. 4 PTP1B ablation or pharmacological inhibition restored trkB tyrosine phosphorylation in LKO mice. a Immunoblot of PFC protein extracts probed with anti-phosphotyrosine-trkB and trkB antibodies (upper panel) revealed lower $p$-trkB in LKO mice that were restored in DKO mice. One-way ANOVA $F_{3,8}=8.713, p=0.0067$. Dunn's post hoc test ${ }^{*} p=0.012$ LKO vs. WT. PTP1B levels (lower panel) were normalized to actin as a loading control. b Mice received a single dose i.p. trodusquemine (Trod, $5 \mathrm{mg} / \mathrm{kg}$ ) or saline vehicle $1 \mathrm{~h}$ prior to harvesting PFC protein. Reduced $p$-trkB levels were restored in LKO mice. One-way ANOVA $F_{3,8}=16.75, p=0.0008$. Dunn's post hoc test ${ }^{*} p=0.0146$ (WT Trod) and 0.0291 (LKO Veh) relative to WT vehicle. Data are means \pm SEM for three mice per group. Representative blots of three mice per genotype.

for the loss of Lmo4 in DKO mice (Supplementary Fig. 2). Whether this is due to a compensatory alteration in other tyrosine phosphatase due to the absence of PTP1B remains to be determined. Of note, ablation of PTP1B in breast cancer cells was reported to induce the expression of PTEN [57]. While we have not examined the effects of trodusquemine on L2/3 PFC pyramidal neuron intrinsic properties or their eCB signaling in LKO mice, our previous study showed this approach could restore eCB signaling from pyramidal neurons at the BLA [18]. Nonetheless, ablation of PTP1B was enough to restore trkB-dependent eCB signaling at the PFC despite overcorrection of neuronal properties.

Targeting another tyrosine phosphatase (PTPN5, aka STEP) has also been reported to ameliorate schizophrenia-like phenotypes in Nrg $1^{+-}$mice by preventing NMDAR loss at the synapse [58]. Our previous studies showed that NMDAR function is intact at the hippocampus in LKO mice [45], suggesting that different mechanisms might be involved in different mouse models used to study schizophrenia. Growing evidence points to uncontrolled tyrosine phosphatase activation in numerous animal models of neurological diseases [41,59].

LKO mice display three negative schizophrenia-like phenotypes: anxiety [18], deficient working memory, and impaired sensorimotor gating. While it could be argued that this model does not have face validity for schizophrenia because the mice do not display social interaction deficits (Supplementary Fig. 2) or hyperlocomotion [18], it is important to point out that Camk2aCre mice only ablate the Lmo4 floxed allele in glutamatergic projection neurons $[18,45]$. Whereas ablating $L m o 4$ in parvalbumin interneurons causes reduced social interaction and repetitive stereotyped behaviors reminiscent of autism spectrum disorders
[33], the consequence of $L m o 4$ ablation in dopaminergic neurons remains to be tested.

LKO mice also develop obesity due to a deficient response of neurons to leptin $[60,61]$ and insulin $[62,63]$ signaling, as a result of the activation PTP1B. Interestingly, several studies have shown that drug-naive schizophrenia patients admitted at the time of their first psychotic episode have insulin resistance compared to age-, sex-, and BMI-matched controls [64-66], suggesting that impaired insulin signaling (particularly in the brain) may contribute to schizophrenia. Leptin levels were also reported to be elevated in schizophrenics [67]. Both insulin and leptin signaling regulate synaptic plasticity and deficits in these pathways could affect cognitive function in animal models [68-72]. Since PTP1B activation is a key mechanism tied to neuronal insulin and leptin resistance [40, 60-63, 73], these studies suggest that PTP1B activation may be a common feature shared by schizophrenics.

Schizophrenia affects the temporal lobes in an asymmetric fashion [74, 75]. The perisylvian cortex is a region associated with language and abnormal asymmetric gene expression in the perisylvian cortex may account for auditory hallucinations in schizophrenia [76, 77]. Intriguingly, LMO4 is expressed asymmetrically during human cortical development, with higher levels in the right than the left perisylvian cortex [78], particularly at the superior temporal gyrus [79]. LMO4 is critical for embryonic cortical development; LMO4 null mice die at birth with exencephaly [39, 80-82]. Interestingly, a high prevalence of rare polymorphisms in the untranslated sequences of LMO4 was reported in patients with schizophrenia [83]. LMO4 expression is suppressed in a viral-induced mouse model of maternal immune activation to induce schizophrenia-like behaviors [84], whereas 
a

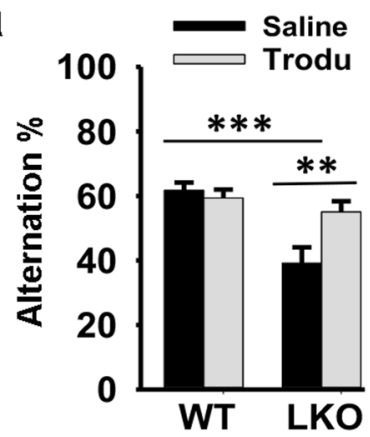

d

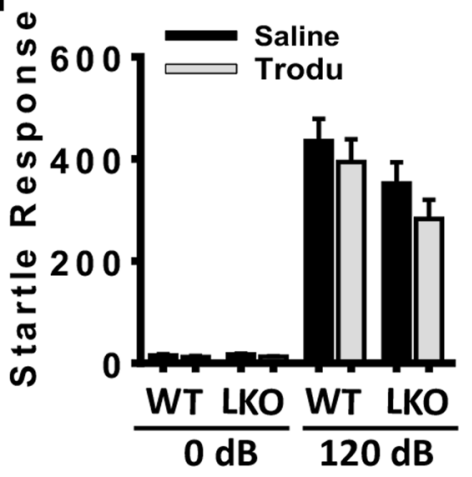

b

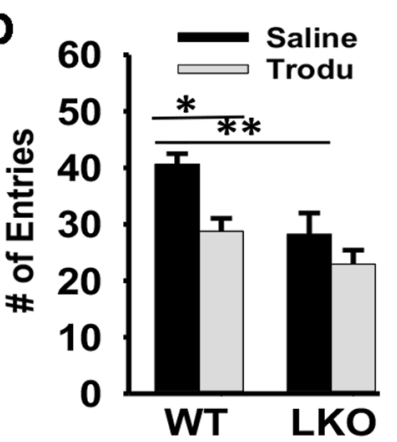

e

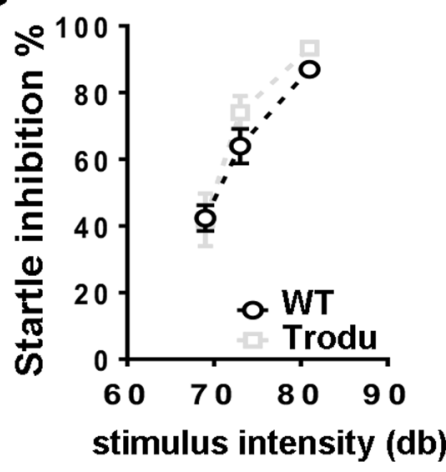

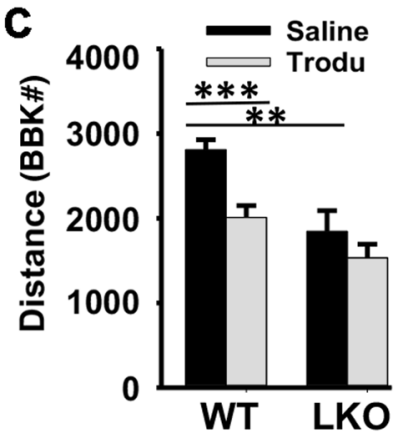

f

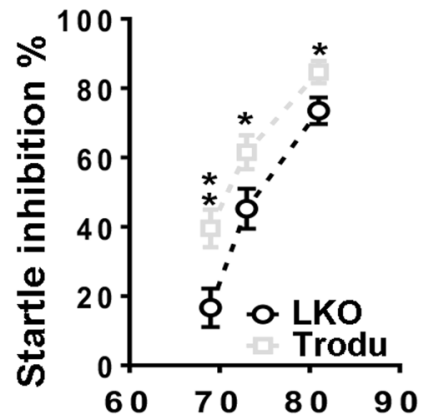

stimulus intensity (db)
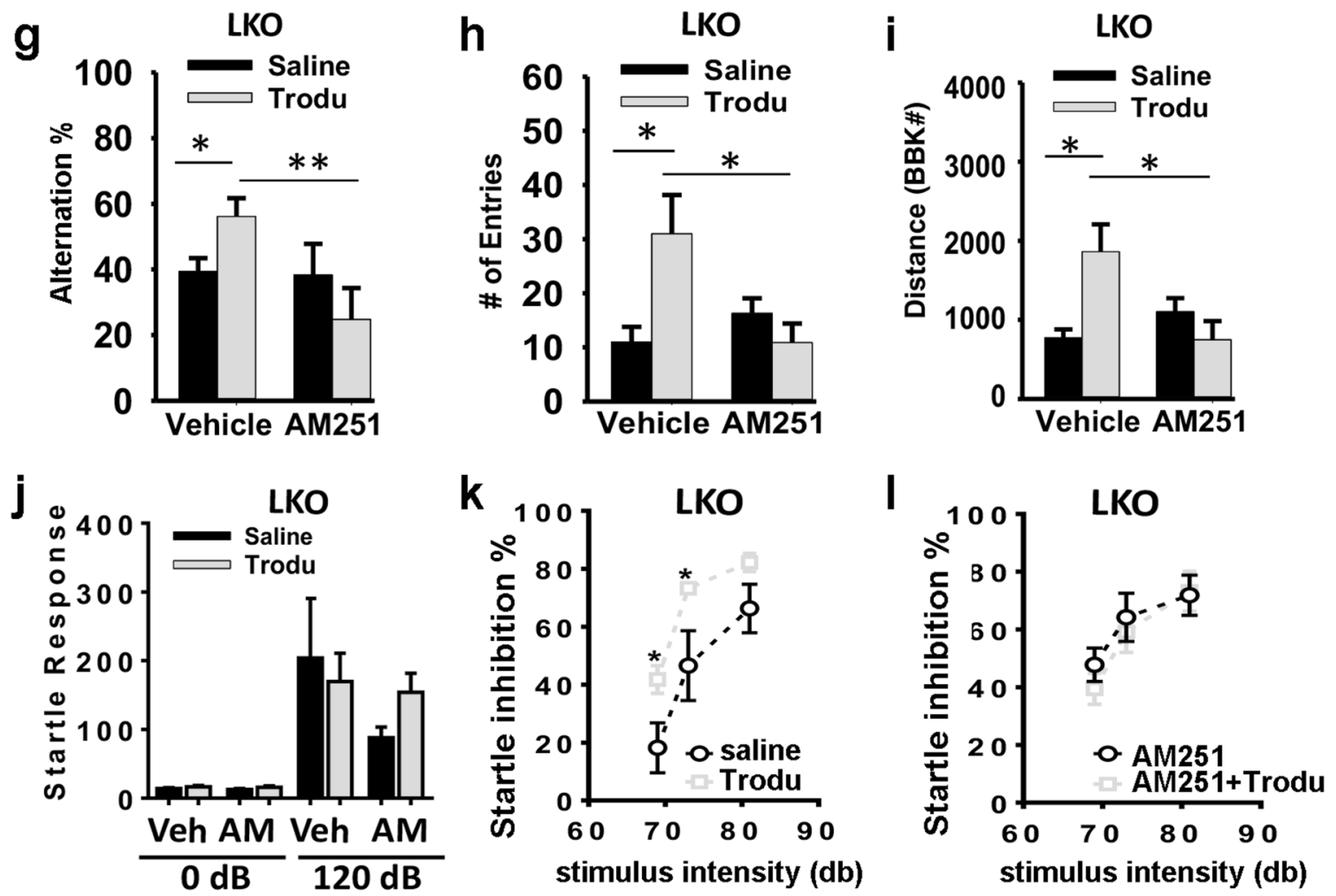

PTP1B is induced by inflammation [85-87]. Maternal infections during pregnancy are implicated in up to one-third of human schizophrenia cases $[2,88,89]$. Infection elevates proinflammatory cytokines in the mother that affect fetal brain development [90]. Whether LMO4 downregulation and PTP1B activation are causally linked to human schizophrenia remains an open question.

In summary, our study suggests that PTP1B represents a novel therapeutic target to ameliorate negative symptoms of schizophrenia. Unlike exogenous cannabinoids that affect inappropriate 
Fig. 5 The effect of PTP1B inhibitor trodusquemine to restore cognitive function and sensorimotor gating in LKO mice was blocked by the CB1 antagonist AM251. a Spatial working memory deficit in LKO mice, assessed by spontaneous alternations in the $Y$ maze, is rescued by $1 \mathrm{~h}$ pretreatment with trodusquemine (Trodu, $5 \mathrm{mg} / \mathrm{kg}$, i.p.). Two-way ANOVA: genotype effect $F_{1,58}=16.05, p=0.0002$; treatment effect $F_{1,58}$ $=4.103, p=0.0474$; interaction $F_{1,58}=7.460, p=0.0083$; Tukey's test ${ }^{* *} p=0.007,{ }^{* * *} p<0.001$. The deficits of LKO mice in the number of entries to the $\mathrm{Y}$ maze (b) or the distance traveled (c) were not improved by trodusquemine. Two-way ANOVA: $\mathbf{b}$ genotype effect $F_{1,58}=12.43$, $p=0.0008$; treatment effect $F_{1,58}=11.01, p=0.0016$; Tukey's test ${ }^{*} p=0.029$, ${ }^{* *} p=0.004$. c Genotype effect $F_{1,58}=18.98, p<0.0001$; treatment effect $F_{1,58}=11.29, p=0.0014$, Tukey's test ${ }^{* *} p=0.004,{ }^{* *} p<0.001$. Trodusquemine did not affect the startle response (d), or sensorimotor gating in WT mice (e), but rescued sensorimotor gating deficiency in LKO mice (f). Two-way ANOVA: $\mathbf{f}$ trodusquemine effect $F_{1,90}=17.82, p<$ 0.0001 ; stimulus intensity effect $F_{2,90}=54.70, p<0.0001$. Post hoc comparison by $t$-test ${ }^{* *} p=0.0061(69 \mathrm{~dB}) ;{ }^{*} p=0.0393(73 \mathrm{~dB}), 0.0326(81 \mathrm{~dB})$. CB1 receptor antagonist AM251 (3 mg/kg, i.p., in 20\% DMSO, $5 \%$ Tween-80 in saline) pretreatment 20 min before trodusquemine abolished the beneficial effects of trodusquemine in the Y-maze test $(\mathbf{g}, \mathbf{h}, \mathbf{i})$ and in the PPI test $(\mathbf{j}, \mathbf{k}, \mathbf{I})$. AM: AM251, Veh: vehicle (20\% DMSO, 5\% Tween80 in saline). g AM251 effect $F_{1,19}=5.186, p=0.0345$, interaction $F_{1,19}=4.670, p=0.0437$. Holm-Sidak test ${ }^{*} p=0.035,{ }^{*} p=0.007$. h interaction $F_{1,20}=8.403, p=0.0089$. Tukey's test ${ }^{*} p=0.0316,0.0198$. i interaction $F_{1,20}=8.659, p=0.0081$. Tukey's test ${ }^{*} p=0.0384,0.0216$. $\mathbf{k}$ Trodusquemine effect $F_{1,27}=15.67, p=0.0005$, stimulus intensity effect $F_{2,27}=21.87, p<0.0001$. Post hoc comparison by $t$-test ${ }^{*} p=0.0334$ $(69 \mathrm{~dB}), 0.0389(73 \mathrm{~dB})$. Data are mean \pm SEM. a-f $n=20 \mathrm{WT}+$ Saline, $13 \mathrm{LKO}+$ Saline, $13 \mathrm{WT}+$ Trodu, $16 \mathrm{LKO}+$ Trodu; $\mathbf{g}-\mathrm{I} n=5 \mathrm{LKO}+$ Saline, 6 LKO + Trodu, 7 LKO + AM251 + Saline, 10 LKO + AM251 + Trodu.

brain regions with unwanted side effects on cognition and have issues of addiction [91], targeting PTP1B hyperactivity to restore eCB signaling in situ, on-demand, would get around these issues.

\section{FUNDING AND DISCLOSURE}

This work was supported by grants from the Ontario of Mental Health Foundation $(\mathrm{HHC})$, the Canadian Institutes of Health Research (\# 376403, HHC), and the Natural Sciences and Engineering Research Council of Canada (\#RGPIN-2019-03942 to HHC; \#RGPIN/2016-04985 to AFRS). The authors declare no competing interests.

\section{AUTHOR CONTRIBUTIONS}

$\mathrm{ZQ}$, AFRS, and HHC were responsible for the study concept and design. ZQ conducted the electrophysiological recordings. SAC performed the western blotting. ZQ conducted the behavioral experiments. ZQ and LZ assisted with data analysis. ZQ $\mathrm{LZ}, \mathrm{AFRS}$, and HHC were responsible for the interpretation of findings. ZQ, AFRS, and HHC drafted and revised the paper. LZ provided critical revision of the paper for important intellectual content. All authors critically reviewed content and approved the final version for publication.

\section{REFERENCES}

1. Brown AS. Prenatal infection as a risk factor for schizophrenia. Schizophr Bull. 2006;32:200-2.

2. Brown AS, Derkits EJ. Prenatal infection and schizophrenia: a review of epidemiologic and translational studies. Am J Psychiatry. 2010;167:261-80.

3. Schizophrenia Working Group of the Psychiatric Genomics C. Biological insights from 108 schizophrenia-associated genetic loci. Nature. 2014;511:421-7.

4. Flint J, Munafo M. Schizophrenia: genesis of a complex disease. Nature. 2014;511:412-3.

5. Winterer G, Weinberger DR. Genes, dopamine and cortical signal-to-noise ratio in schizophrenia. Trends Neurosci. 2004;27:683-90.

6. Vrijenhoek T, Buizer-Voskamp JE, van der Stelt I, Strengman E, Genetic R, Outcome in Psychosis C. et al. Recurrent CNVs disrupt three candidate genes in schizophrenia patients. Am J Hum Genet. 2008;83:504-10.

7. Hyman SE, Fenton WS. Medicine. What are the right targets for psychopharmacology? Science. 2003;299:350-1.

8. Keefe RS, Fenton WS. How should DSM-V criteria for schizophrenia include cognitive impairment? Schizophr Bull. 2007;33:912-20.

9. Reichenberg A, Caspi A, Harrington H, Houts R, Keefe RS, Murray RM, et al. Static and dynamic cognitive deficits in childhood preceding adult schizophrenia: a 30year study. Am J Psychiatry. 2010;167:160-9.

10. Achim AM, Maziade M, Raymond E, Olivier D, Merette C, Roy MA. How prevalent are anxiety disorders in schizophrenia? A meta-analysis and critical review on a significant association. Schizophr Bull. 2011;37:811-21.

11. Boden MT, Babson KA, Vujanovic AA, Short NA, Bonn-Miller MO. Posttraumatic stress disorder and cannabis use characteristics among military veterans with cannabis dependence. Am J Addict. 2013;22:277-84.

12. Bouri $S$, Hanane $H$, Idrissi KEA, Berraho MA, Abdellaoui A, Badiaa $L$, et al. Determining factors for Cannabis use among Moroccans Schizophrenic patients: a cross sectional study. Avicenna J Phytomed. 2020;10:89-100.
13. Lejoyeux M, Basquin A, Koch M, Embouazza $H$, Chalvin F, llongo M. Cannabis use and dependence among French Schizophrenic inpatients. Front Psychiatry. 2014;5:82.

14. Hunt GE, Large MM, Cleary M, Lai HMX, Saunders JB. Prevalence of comorbid substance use in schizophrenia spectrum disorders in community and clinical settings, 1990-2017: systematic review and meta-analysis. Drug Alcohol Depend. 2018;191:234-58.

15. Di Forti M, Morgan C, Dazzan P, Pariante C, Mondelli V, Marques TR, et al. Highpotency cannabis and the risk of psychosis. Br J Psychiatry. 2009;195:488-91.

16. Kingwell K. Synaptic plasticity: a new partnership. Nat Rev Neurosci. 2011;12:5.

17. Lomazzo E, Bindila L, Remmers F, Lerner R, Schwitter C, Hoheisel U, et al. Therapeutic potential of inhibitors of endocannabinoid degradation for the treatment of stress-related hyperalgesia in an animal model of chronic pain. Neuropsychopharmacology. 2015;40:488-501.

18. Qin Z, Zhou X, Pandey NR, Vecchiarelli HA, Stewart CA, Zhang X, et al. Chronic stress induces anxiety via an amygdalar intracellular cascade that impairs endocannabinoid signaling. Neuron. 2015;85:1319-31.

19. Freund TF, Katona I, Piomelli D. Role of endogenous cannabinoids in synaptic signaling. Physiol Rev. 2003;83:1017-66.

20. Alger BE. Retrograde signaling in the regulation of synaptic transmission: focus on endocannabinoids. Prog Neurobiol. 2002;68:247-86.

21. Andreasson S, Allebeck P, Engstrom A, Rydberg U. Cannabis and schizophrenia. A longitudinal study of Swedish conscripts. Lancet. 1987;2:1483-6.

22. Volk DW, Siegel BI, Verrico CD, Lewis DA. Endocannabinoid metabolism in the prefrontal cortex in schizophrenia. Schizophr Res. 2013;147:53-7.

23. Braff DL, Light GA, Swerdlow NR. Prepulse inhibition and P50 suppression are both deficient but not correlated in schizophrenia patients. Biol Psychiatry. 2007:61:1204-7.

24. Malone DT, Taylor DA. The effect of delta9-tetrahydrocannabinol on sensorimotor gating in socially isolated rats. Behavioural Brain Res. 2006;166:101-9.

25. Brzozka MM, Fischer A, Falkai $P$, Havemann-Reinecke U. Acute treatment with cannabinoid receptor agonist WIN55212.2 improves prepulse inhibition in psychosocially stressed mice. Behavioural Brain Res. 2011;218:280-7.

26. Levin R, Peres FF, Almeida V, Calzavara MB, Zuardi AW, Hallak JE, et al. Effects of cannabinoid drugs on the deficit of prepulse inhibition of startle in an animal model of schizophrenia: the SHR strain. Front Pharmacol. 2014;5:10.

27. Spano MS, Fadda P, Frau R, Fattore L, Fratta W. Cannabinoid self-administration attenuates PCP-induced schizophrenia-like symptoms in adult rats. Eur Neuropsychopharmacol. 2010;20:25-36.

28. Lee TT, Filipski SB, Hill MN, McEwen BS. Morphological and behavioral evidence for impaired prefrontal cortical function in female $C B 1$ receptor deficient mice. Behavioural Brain Res. 2014;271:106-10.

29. Ortega-Alvaro A, Navarrete F, Aracil-Fernandez A, Navarro D, Berbel P, Manzanares J. Differential pharmacological regulation of sensorimotor gating deficit in CB1 knockout mice and associated neurochemical and histological alterations. Neuropsychopharmacology. 2015;40:2639-47.

30. Hill MN, Hillard CJ, McEwen BS. Alterations in corticolimbic dendritic morphology and emotional behavior in cannabinoid $\mathrm{CB} 1$ receptor-deficient mice parallel the effects of chronic stress. Cereb Cortex. 2011;21:2056-64.

31. Zamberletti E, Piscitelli F, Cadeddu F, Rubino T, Fratta W, Fadda P, et al. Chronic blockade of $\mathrm{CB}(1)$ receptors reverses startle gating deficits and associated neurochemical alterations in rats reared in isolation. $\mathrm{Br} J$ Pharmacol. 2012;167:1652-64.

32. Collins DP, Anastasiades PG, Marlin JJ, Carter AG. Reciprocal circuits linking the prefrontal cortex with dorsal and ventral thalamic nuclei. Neuron. 2018;98:366-79.e4. 
33. Zhang L, Qin Z, Ricke KM, Cruz SA, Stewart AFR, Chen HH. Hyperactivated PTP1B phosphatase in parvalbumin neurons alters anterior cingulate inhibitory circuits and induces autism-like behaviors. Nat Commun. 2020;11:1017.

34. Yang ST, Shi Y, Wang Q, Peng JY, Li BM. Neuronal representation of working memory in the medial prefrontal cortex of rats. Mol Brain. 2014;7:61.

35. Japha K, Koch M. Picrotoxin in the medial prefrontal cortex impairs sensorimotor gating in rats: reversal by haloperidol. Psychopharmacology. 1999;144:347-54.

36. Lemtiri-Chlieh F, Levine ES. BDNF evokes release of endogenous cannabinoids at layer $2 / 3$ inhibitory synapses in the neocortex. J Neurophysiol. 2010;104:1923-32.

37. Ozek C, Kanoski SE, Zhang ZY, Grill HJ, Bence KK. Protein-tyrosine phosphatase 1B (PTP1B) is a novel regulator of central brain-derived neurotrophic factor and tropomyosin receptor kinase B (TrkB) signaling. J Biol Chem. 2014;289:31682-92.

38. Casanova $E$, Fehsenfeld $S$, Mantamadiotis $T$, Lemberger $T$, Greiner $E$, Stewart AF, et al. A CamKIla iCre BAC allows brain-specific gene inactivation. Genesis. 2001;31:37-42.

39. Hahm K, Sum EY, Fujiwara Y, Lindeman GJ, Visvader JE, Orkin SH. Defective neural tube closure and anteroposterior patterning in mice lacking the LIM protein LMO4 or its interacting partner Deaf-1. Mol Cell Biol. 2004;24:2074-82.

40. Bence KK, Delibegovic M, Xue B, Gorgun CZ, Hotamisligil GS, Neel BG, et al. Neuronal PTP1B regulates body weight, adiposity and leptin action. Nat Med. 2006;12:917-24.

41. Ricke KM, Cruz SA, Qin Z, Farrokhi K, Sharmin F, Zhang L, et al. Neuronal protein tyrosine phosphatase 1B hastens amyloid beta-associated Alzheimer's disease in mice. J Neurosci. 2020;40:1581-93.

42. Ahima RS, Patel HR, Takahashi N, Qi Y, Hileman SM, Zasloff MA. Appetite suppression and weight reduction by a centrally active aminosterol. Diabetes. 2002:51:2099-104.

43. Zasloff M, Williams Jl, Chen Q, Anderson M, Maeder T, Holroyd K, et al. A spermine-coupled cholesterol metabolite from the shark with potent appetite suppressant and antidiabetic properties. Int J Obes Relat Metab Disord. 2001;25:689-97.

44. Franklin $\mathrm{K}$, Paxinos $\mathrm{G}$. The mouse brain in stereotaxic coordinates, compact. 3rd ed. Academic Press; San Diego, 2008

45. Qin Z, Zhou X, Gomez-Smith M, Pandey NR, Lee KF, Lagace DC, et al. LIM domain only 4 (LMO4) regulates calcium-induced calcium release and synaptic plasticity in the hippocampus. J Neurosci. 2012;32:4271-83.

46. Wilson RI, Nicoll RA. Endogenous cannabinoids mediate retrograde signalling at hippocampal synapses. Nature. 2001;410:588-92.

47. Schock SC, Xu J, Duquette PM, Qin Z, Lewandowski AJ, Rai PS, et al. Rescue of neurons from ischemic injury by peroxisome proliferator-activated receptorgamma requires a novel essential cofactor LMO4. J Neurosci. 2008;28:12433-44.

48. Gomez-Smith M, Qin Z, Zhou X, Schock SC, Chen HH. LIM domain only 4 protein promotes granulocyte colony-stimulating factor-induced signaling in neurons. Cell Mol life Sci. 2010;67:949-57.

49. Ramirez DM, Kavalali ET. Differential regulation of spontaneous and evoked neurotransmitter release at central synapses. Curr Opin Neurobiol. 2011;21:275-82.

50. Nakazawa T, Hashimoto R, Sakoori K, Sugaya $Y$, Tanimura A, Hashimotodani $Y$, et al. Emerging roles of ARHGAP33 in intracellular trafficking of TrkB and pathophysiology of neuropsychiatric disorders. Nat Commun. 2016;7:10594.

51. Zhong P, Liu Y, Hu Y, Wang T, Zhao YP, Liu QS. BDNF interacts with endocannabinoids to regulate cocaine-induced synaptic plasticity in mouse midbrain dopamine neurons. J Neurosci. 2015;35:4469-81.

52. Fortin DA, Levine ES. Differential effects of endocannabinoids on glutamatergic and GABAergic inputs to layer 5 pyramidal neurons. Cereb Cortex. 2007:17:163-74.

53. Zhao L, Levine ES. BDNF-endocannabinoid interactions at neocortical inhibitory synapses require phospholipase C signaling. J Neurophysiol. 2014;111:1008-15.

54. Zhao L, Yeh ML, Levine ES. Role for endogenous BDNF in endocannabinoidmediated long-term depression at neocortical inhibitory synapses. eNeuro. 2015:2:2.

55. Robbe D, Alonso G, Duchamp F, Bockaert J, Manzoni OJ. Localization and mechanisms of action of cannabinoid receptors at the glutamatergic synapses of the mouse nucleus accumbens. J Neurosci. 2001;21:109-16.

56. Chevaleyre V, Takahashi KA, Castillo PE. Endocannabinoid-mediated synaptic plasticity in the CNS. Annu Rev Neurosci. 2006;29:37-76.

57. Liu X, Chen Q, Hu XG, Zhang XC, Fu TW, Liu Q, et al. PTP1B promotes aggressiveness of breast cancer cells by regulating PTEN but not EMT. Tumour Biol. 2016;37:13479-87.

58. Xu J, Hartley BJ, Kurup P, Phillips A, Topol A, Xu M, et al. Inhibition of STEP61 ameliorates deficits in mouse and hiPSC-based schizophrenia models. Mol Psychiatry. 2018;23:271-81.

59. Stewart AFR, Chen HH. Activation of tyrosine phosphatases in the progression of Alzheimer's disease. Neural Regen Res. 2020;15:2245-6.
60. Pandey NR, Zhou X, Qin Z, Zaman T, Gomez-Smith M, Keyhanian K, et al. The LIM domain only 4 protein is a metabolic responsive inhibitor of protein tyrosine phosphatase 1B that controls hypothalamic leptin signaling. J Neurosci. 2013;33:12647-55

61. Zhou X, Gomez-Smith M, Qin Z, Duquette PM, Cardenas-Blanco A, Rai PS, et al. Ablation of $\mathrm{LMO} 4$ in glutamatergic neurons impairs leptin control of fat metabolism. Cell Mol life Sci. 2012;69:819-28.

62. Pandey NR, Zhou X, Zaman T, Cruz SA, Qin Z, Lu M, et al. LMO4 is required to maintain hypothalamic insulin signaling. Biochem Biophys Res Commun. 2014;450:666-72.

63. Qin Z, Pandey NR, Zhou X, Stewart CA, Hari A, Huang H, et al. Functional properties of claramine: a novel PTP1B inhibitor and insulin-mimetic compound. Biochem Biophys Res Commun. 2015;458:21-7.

64. Petrikis P, Tigas S, Tzallas AT, Papadopoulos I, Skapinakis P, Mavreas V. Parameters of glucose and lipid metabolism at the fasted state in drug-naive first-episode patients with psychosis: evidence for insulin resistance. Psychiatry Res. 2015;229:901-4.

65. van Nimwegen LJ, Storosum JG, Blumer RM, Allick G, Venema HW, de Haan L, et al. Hepatic insulin resistance in antipsychotic naive schizophrenic patients: stable isotope studies of glucose metabolism. J Clin Endocrinol Metab. 2008;93:572-7.

66. Dasgupta A, Singh OP, Rout JK, Saha T, Mandal S. Insulin resistance and metabolic profile in antipsychotic naive schizophrenia patients. Prog Neuropsychopharmacol Biol Psychiatry. 2010;34:1202-7.

67. Stubbs B, Wang AK, Vancampfort D, Miller BJ. Are leptin levels increased among people with schizophrenia versus controls? A systematic review and comparative meta-analysis. Psychoneuroendocrinology. 2016;63:144-54.

68. Nicolas CS, Peineau S, Amici M, Csaba Z, Fafouri A, Javalet C, et al. The Jak/STAT pathway is involved in synaptic plasticity. Neuron. 2012;73:374-90.

69. Dou JT, Chen M, Dufour F, Alkon DL, Zhao WQ. Insulin receptor signaling in longterm memory consolidation following spatial learning. Learn Mem. $2005 ; 12: 646-55$

70. Ahmadian G, Ju W, Liu L, Wyszynski M, Lee SH, Dunah AW, et al. Tyrosine phosphorylation of GluR2 is required for insulin-stimulated AMPA receptor endocytosis and LTD. EMBO J. 2004;23:1040-50.

71. Shanley LJ, Irving AJ, Harvey J. Leptin enhances NMDA receptor function and modulates hippocampal synaptic plasticity. J Neurosci. 2001;21:RC186.

72. Irving AJ, Harvey J. Leptin regulation of hippocampal synaptic function in health and disease. Philos Trans R Soc Lond B Biol Sci. 2014;369:20130155.

73. Dodd GT, Xirouchaki CE, Eramo M, Mitchell CA, Andrews ZB, Henry BA, et al. Intranasal targeting of hypothalamic PTP1B and TCPTP reinstates Leptin and insulin sensitivity and promotes weight loss in obesity. Cell Rep. 2019;28:2905-22. e5.

74. Ribolsi M, Daskalakis ZJ, Siracusano A, Koch G. Abnormal asymmetry of brain connectivity in schizophrenia. Front Hum Neurosci. 2014;8:1010.

75. Crow TJ. Temporal lobe asymmetries as the key to the etiology of schizophrenia. Schizophr Bull. 1990;16:433-43.

76. Catani M, Craig MC, Forkel SJ, Kanaan R, Picchioni M, Toulopoulou T, et al. Altered integrity of perisylvian language pathways in schizophrenia: relationship to auditory hallucinations. Biol Psychiatry. 2011;70:1143-50.

77. Hugdahl K, Loberg EM, Specht K, Steen VM, van Wageningen $H$, Jorgensen HA. Auditory hallucinations in schizophrenia: the role of cognitive, brain structural and genetic disturbances in the left temporal lobe. Front Hum Neurosci. 2007;1:6.

78. Sun T, Patoine C, Abu-Khalil A, Visvader J, Sum E, Cherry TJ, et al. Early asymmetry of gene transcription in embryonic human left and right cerebral cortex. Science. 2005;308:1794-8.

79. Abrahams BS, Tentler D, Perederiy JV, Oldham MC, Coppola G, Geschwind DH. Genome-wide analyses of human perisylvian cerebral cortical patterning. Proc Natl Acad Sci USA. 2007;104:17849-54.

80. Tse E, Smith AJ, Hunt S, Lavenir I, Forster A, Warren AJ, et al. Null mutation of the Lmo4 gene or a combined null mutation of the Lmo1/Lmo3 genes causes perinatal lethality, and Lmo4 controls neural tube development in mice. Mol Cell Biol. 2004;24:2063-73.

81. Lee SK, Jurata LW, Nowak R, Lettieri K, Kenny DA, Pfaff SL, et al. The LIM domainonly protein $\mathrm{LMO} 4$ is required for neural tube closure. Mol Cell Neurosci. 2005;28:205-14.

82. Duquette PM, Zhou X, Yap NL, MacLaren EJ, Lu JJ, Wallace VA, et al. Loss of LMO4 in the retina leads to reduction of GABAergic amacrine cells and functional deficits. PloS ONE. 2010;5:e13232.

83. Levchenko A, Davtian S, Petrova N, Malashichev Y. Sequencing of five left-right cerebral asymmetry genes in a cohort of schizophrenia and schizotypal disorder patients from Russia. Psychiatr Genet. 2014;24:75-80.

84. Fatemi SH, Pearce DA, Brooks Al, Sidwell RW. Prenatal viral infection in mouse causes differential expression of genes in brains of mouse progeny: a potential animal model for schizophrenia and autism. Synapse. 2005;57:91-9. 
85. Zabolotny JM, Kim YB, Welsh LA, Kershaw EE, Neel BG, Kahn BB. Protein-tyrosine phosphatase $1 \mathrm{~B}$ expression is induced by inflammation in vivo. J Biol Chem 2008;283:14230-41.

86. Nieto-Vazquez I, Fernandez-Veledo $\mathrm{S}$, de Alvaro $\mathrm{C}$, Lorenzo $\mathrm{M}$. Dual role of interleukin-6 in regulating insulin sensitivity in murine skeletal muscle. Diabetes. 2008;57:3211-21.

87. Zhu X, Zhou Y, Tao R, Zhao J, Chen J, Liu C, et al. Upregulation of PTP1B after rat spinal cord injury. Inflammation. 2015;38:1891-902.

88. Buka SL, Tsuang MT, Torrey EF, Klebanoff MA, Wagner RL, Yolken RH. Maternal cytokine levels during pregnancy and adult psychosis. Brain Behav Immun. $2001 ; 15: 411-20$
89. Brown AS, Hooton J, Schaefer CA, Zhang H, Petkova E, Babulas V, et al. Elevated maternal interleukin-8 levels and risk of schizophrenia in adult offspring. Am J Psychiatry. 2004;161:889-95.

90. Gilmore JH, Fredrik Jarskog L, Vadlamudi S, Lauder JM. Prenatal infection and risk for schizophrenia: IL-1beta, IL-6, and TNFalpha inhibit cortical neuron dendrite development. Neuropsychopharmacology. 2004;29:1221-9.

91. Solowij N, Stephens RS, Roffman RA, Babor T, Kadden R, Miller M, et al. Cognitive functioning of long-term heavy cannabis users seeking treatment. JAMA. 2002;287:1123-31. 